\title{
Modeling of railway vehicles movement having deviations in content of running parts
}

\author{
Petrov Gennadiy \\ Railway Cars and Rolling Stock Department \\ Russian university of transport (MIIT) \\ Moscow, Russia
}

PetrovGI@gmail.com

\author{
Tarmaev Anatoliy ${ }^{\mathrm{a}, \mathrm{b}}$ \\ Railway Cars and Rolling Stock Department \\ a) Irkutsk state railway transport university \\ Irkutsk, Russia \\ b) Russian university of transport (MIIT) \\ Moscow, Russia \\ t38_69@mail.ru
}

\begin{abstract}
The need for an accurate mathematical description of the dynamic processes occurring in the running parts of the railway vehicles is substantiated, taking into account the real operating conditions of the rolling stock. A mathematical model of motion of vehicles with a variable structure of a system of nonlinear differential equations of motion is proposed. In the design scheme, material elements are accepted by massive rigid bodies, whose internal deformations are not taken into account in calculations, and by elastic-friction elements with nonlinear characteristics, whose masses are neglected. Between the elements of the system, connections are used that regulate certain relative movements of these elements. Features of dynamic power connections in the «wheel pair-path» system are taken into account, including rolling, sliding and slipping of wheel crests along the lateral faces of railheads arising in motion. To do this, a special technique is used to calculate the longitudinal and transverse forces of wheel-rail friction depending on the redistribution of the relative rates of slippage, lateral attitude, wagging and twitching of the wheel pair. The mathematical model allows one to investigate the movement, dynamic properties of the railway vehicles taking into account the real combinations of the maximum permissible wear of the running parts of the vehicles and the track; choose rational parameters of the railway vehicles for various geometric, rigid and inertial parameters of the running gear of the vehicle.
\end{abstract}

Keywords - railway vehicle; mathematical model; the «wheel pair-track» system, car dinamics; car truck.

\section{INTRODUCTION}

A large number of violations of the safety of the movement of railway vehicles are observed in the presence of deviations in the content of their running parts and the upper structure of the track in curved sections of the track. For the analysis of traffic safety estimating the influence of deviations in content, and choosing rational parameters of structural elements, a mathematical model is needed that accurately describes the dynamic processes occurring during the interaction of the «wheel pair-track» system in the sprung and non-sprung parts of the vehicle. A large number of papers have been devoted to modeling the motion of railway carriages in which as a rule the theory of «creep» with various refinements of the equations of motion is used [1, 2]. In modeling, specialized computer programs of engineering analysis are used [3-7]. In a number of works, the dynamic interactions of the «wheel-rail» system are considered taking into account deviations in the content of the running parts of the vehicles and the track [8-13]. At the same time in numerical simulation some features of dynamic power connections are not fully taken into account taking into account the rolling, sliding and slipping of wheels along the lateral faces of railheads arising in motion.

\section{SIMULATION APPROACH}

To describe the motion of the railway vehicle, an approach based on the theory of relative motion using moving noninertial local coordinate systems is used [14]. A fixed coordinate system $\tilde{O} \xi \eta \zeta$ and two mobiles are used: natural - is $O x y z$ and associated with a solid $-C x^{\prime} y^{\prime} z^{\prime}$, where $C x^{\prime}, C y^{\prime}, C z^{\prime}$ - main central axes of inertia (Fig. 1). All coordinate systems are right. The origin of the absolute fixed (Cartesian) coordinate system is located on the straight track at the beginning of the transition curve. The axes of the natural coordinate system $O x y z$ are directed respectively along the tangent, normal and binormal to the path axis. All the solid bodies of the system have the main central axes of inertia and the resulting relative motions are the geometric sum of the motions in the individual coordinate planes. To establish the dependencies between the projections of the angular velocities of rotation of a rigid body on fixed and moving coordinate axes, the Euler kinematic equations are used taking into account the smallness of the angular velocities of rotation around its own axes.

Let us consider as a railway vehicle 4-axle car (Figure 2). The object is represented by a system of 11 solid bodies (a body, two bolster cross-member, four side frames, four wheel pairs) connected with each other by elastic-friction non-linear bonds.

The assumption of the non-deformability of bodies is based on the fact that the rigidity of spring suspension and elastic bonds is much less than the structural rigidity of the frames of bogies and the superstructure and the frequency of elastic vibrations of these bodies is much higher than the frequency of their vibrations on the spring suspension. 


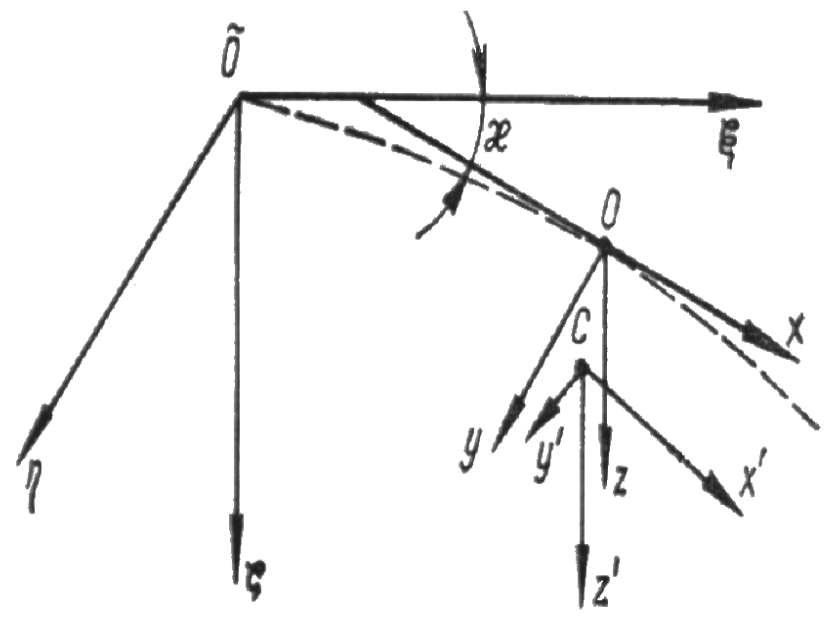

Fig. 1. Reference systems for solids

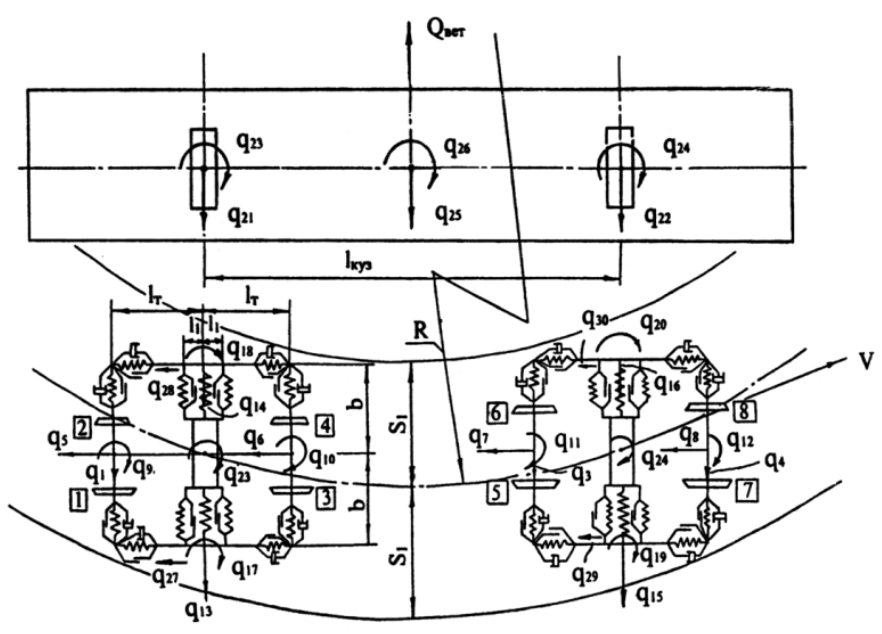

Fig. 2. The calculation scheme of the four-axle vehicle

The load in the car is considered to be undeformable and integrated into the body of the car.

Between the elements of the system, connections are used that regulate certain relative movements of these elements.

At the junction of the side frame (SF) and the wheel pair (WP) there are elastic-dissipative bonds with a gap, as a result of which relative translational, lateral and angular movements are possible.

As a result of the presence of elastic-friction bonds with a gap between the bolster cross-member (BCM) and the SF, their relative transverse and angular displacements in the horizontal plane are possible. Running of one SF relative to the other occurs as a result of their connection through the $\mathrm{BCM}$ and spring sets.

Frictional connections between the body and the BCM allow angular relative movements in the horizontal plane. Relative translational movements in the first stage are not considered, because in the standard design of the male center plate node there are no elastic elements. In addition, the gaps between male and female center plate are neglected.
The redistribution of the vertical load on the rails occurs as a result of the elevation of the outer rail over the inner rail in curvilinear sections of the track. This takes into account the gaps in the slips and the properties of suspension in the vertical direction.

The model takes into account the following features and nonlinearities that affect the horizontal dynamics of the vehicle: the action of the moments of the forces of dry friction in the plane of the support of the foot on the thrust bearing, the possibility of installing dampers of viscous and dry friction in the junction of the gearbox with the SF and the presence of gaps in this assembly, and railheads, one-sidedness of the connection between the wheel and the rail, the SF with the WP, the clearance in the rut, the nonlinear character of the creep forces taking into account the rolling principle of the wheels N.E. Zhukovsky.

Possible displacements of bodies are described by the following relative generalized coordinates $q$ (Figure 2): $q_{1} \ldots q_{4}$ - horizontal linear transverse displacements WP; $q_{5} \ldots q_{8}-$ horizontal linear longitudinal displacements WP; $q_{9} \ldots q_{12}-$ horizontal displacement plane WP; $q_{13} \ldots q_{16}$-horizontal linear transverse movements SF; $q_{17} \ldots q_{20}$-angular in the horizontal plane of displacement SF; $q_{23} \ldots q_{24}$-angular in the horizontal plane of displacement BCM; $q_{25}$-horizontal transverse linear movements of the body; $q_{26}-$ angular in the horizontal plane of movement of the body; $q_{27} \ldots q_{30}-$ horizontal linear longitudinal displacements SF.

The movement of the 4-axle car is described by a system of the 60th order of 30 differential equations, corresponds to the accepted calculation scheme of the car (Figure 2) and includes the equations of dynamic equilibrium:

- WP on forces parallel to the axis $Y$, axis $X$;

- by the sum of the moments of forces acting on each WP relative to the axis $X$;

- SF on forces parallel to the axis $Y$, axis $X$, on the moments of forces, rotating SF in plane;

- $\mathrm{BCM}$ on the moments of forces, trying to rotate $\mathrm{B}$ relatively kingpins;

- body on the forces acting on it and the moments of forces.

In the design scheme possible increments in the coordinates of the system the values of the deformation of the connections between the bodies of the system are determined on the basis of the well-known assumption that the angles between the axes of moving coordinate systems associated with the center of mass and the path axis are small for each solid (their values are not exceed $0.005 \mathrm{rad}$ ) and their cosines are equal to 1 , and the sinuses and tangents to the angle value.

The calculation scheme material elements taken massive rigid bodies of which the internal strain in the calculations are not captured and an elastically-friction elements with nonlinear characteristics the masses are neglected.

For each element of the system, there is its own adopted mobile coordinate system, the center of which is in the center of mass of each element.

Dynamic deformations of WP and SF bonds are determined in the transverse and longitudinal directions and 
BCM and SF are determined by their mutual wobble and transverse displacements in time. Dynamic deformations of the «wheel-rail» connections are calculated taking into account the unevenness and broadening of the rail threads, the elastic depressions and the lateral displacements of the gear unit in time. We check the condition of each ridge on the rail taking into account the clearance in the ridge to the side, the running and friction of the ridge against the side surface of the railhead [15].

When investigating the movement of the railway vehicle in curves, the linearization of the wheel profile cannot be accepted. Therefore the model reflects the action of «gravitational» stiffness: in the case when the point of contact on one wheel is displaced closer to the ridge due to the nonlinearity of the profile the difference of the contact angles arises and consequently even with the same vertical loads on both wheels the transverse components of the normal forces will be different which will lead to the appearance of a returning lateral force. Its value increases with increasing lateral displacement of the gear unit and is determined from the expressions given in [16] for the real rolling profile of the wheel and rail.

When determining the vertical reactions of rails under each wheel the redistribution of the vertical load between the outer and inner rail threads is taken into account as a result of their elevation as well as the action of the moments of the transverse inertial forces.

In connection with the fact that in the case of curvilinear motion a significant slippage of wheels is possible, the application of linear theories of determining the creep forces and their moments is unacceptable.

Therefore when simulating the movement of the vehicle, the principle of N.E. Zhukovsky describes the movement of wheels in the WP and a special technique for calculating the longitudinal and transverse forces of wheel-rail friction depending on the redistribution of the relative rates of slippage, lateral attitude, wagging and jerking WP.

Longitudinal and transverse reactions of SF bonds with WP bays (Figure 3) are determined on the basis that the case of the axle box can simultaneously slide and rotate relative to the supporting frictional surface of the pedestrian opening of the SF due to oscillation of wiggling, twitching and lateral attitude of the gearbox. This takes into account the presence of a spread of longitudinal and transverse gaps, the forces of dry friction on the bearing surface and when choosing a gap, angular pinching in the plan and the possibility of installing various elastic-friction elements in the joint of the axle box with the SF.

The connection of the SF with the BCM of the truck is carried out through the springs of the central spring suspension, the subclinical springs and the friction wedges therefore the coupling reactions are defined as the sum of the forces of the elastic components of the spring set and the forces of dry friction realized by the absorber taking into account the action of the returning and pinching moments and forces in the oscillations of wobble and the running of SF.

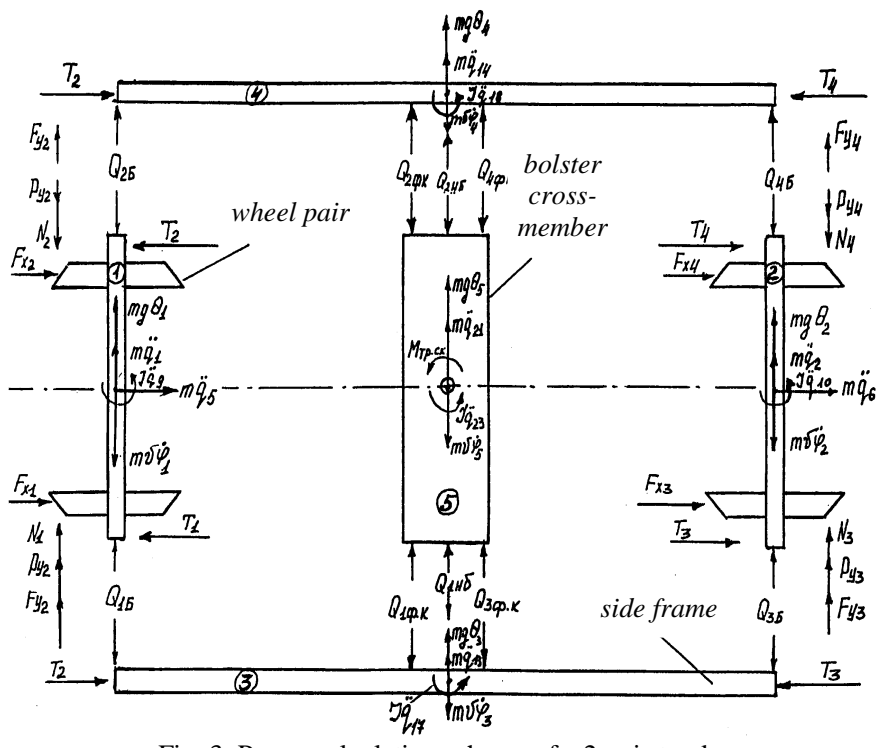

Fig. 3. Power calculation scheme of a 2-axis truck

Expressions for the damping moments arising from angular relative movements of the body and the BCM in the plane of their support in the pivot assemblies were obtained by integrating the moments of the friction forces along the area of the contacting surfaces with respect to the elementary areas taking into account the external and internal radius of the Friday and the signature dependence of the direction of their action:

$$
M_{f r j}=\frac{2}{3} \cdot \mu \cdot P_{j} \frac{R_{2}^{3}-R_{1}^{3}}{R_{2}^{2}-R_{1}^{2}} \operatorname{sign}\left(\dot{q}_{j}-\dot{q}_{26}\right)
$$

where $\mu$ is the coefficient of friction in the male center plate node; $P_{j}$ is the load on the male center plate; $R_{2}, R_{I}$ - are external and internal radius male center plate, respectively; $\dot{q}_{j}$, $\dot{q}_{26}$ is the first time derivative of wobble $j$ BCM and body, respectively.

The mutual angular and linear displacements of the conjugate elements in the truck are determined:

- linear movements of the gearbox relative to the SF in the function of the coordinates of the wheel pair and the SF;

- transverse movements of the BCM relative to the SF;

- transverse movements of friction wedges of spring suspension by friction strips;

- mutual transverse displacements of the points of the rolling surfaces of the wheels relative to the points of the rolling surfaces along the railheads:

$$
\Delta_{i \kappa p}=q_{i}+y_{i}(t)-y_{p i},
$$

where $q_{i}$ is the generalized coordinate of lateral displacement $\mathrm{WP} ; y_{i}(t)$ is the ordinate of the geometric unevenness of the path under $i$ wheel; $y_{p i}$ is the elastic rail release under $i$ wheel.

The vertical loads from the wheels to the rails are determined: 
- lateral loads on the body under the action of transverse acceleration on it from the centrifugal and centripetal forces of inertia:

$$
H_{b}=0,5 \cdot G_{b} \cdot\left(\frac{V^{2}}{R}-\frac{g \cdot h}{2 \cdot S}\right),
$$

where $G_{b}$ is the body weight; $V$ - is the vehicle speed along a curve; $h$ is the elevation of the outer rail of the curve, $\mathrm{m} ; g=$ $9,81 \mathrm{~m} / \mathrm{s}^{2} ; S$ is a half distance between the centers of the railheads in the track;

- angles of body rotation due to deformations of spring suspension and transfer to slipways. Angle of transshipment of the body on the sides $\beta_{s}=\frac{\delta}{b_{0}-R_{2}} \cdot \delta$, where $\delta-$ is the gap in slippery; $b_{0}-$ is the distance from the center of the kingpin to the center of the hood on the slope; $R_{2}-$ is the outer radius of thrust bearing. Body angle is due to spring deformations $\beta$ $=\frac{\mathrm{H}_{b} \cdot h_{b} \cdot G_{b} \cdot h_{\mathrm{K \kappa}} \cdot \beta_{b}}{\mathrm{C}_{\mathrm{y} \varphi}-G_{b} \cdot h_{b}}$, where $h_{b}$ is the height of the center of gravity of the body from the lower plane of the spring suspension of the car; $C_{y \varphi}$ is the angular rigidity of spring suspension, determined by the formula $C_{y \varphi}=2 \cdot C_{z} \cdot b_{Z}^{2}$, where $C_{z}$ is the vertical rigidity of the spring set; $b_{z}$ is the distance from the center of the spring set to the axis of the trolley passing through the pivot;

- load on the neck of the gearbox caused by the action on the wagon of centrifugal and centripetal acceleration.

Empirical dependencies have been adopted as a relationship between the moment of rotation of the $\mathrm{BCM}$ and its angle of rotation relative to the SF.

Force reactions of the boxes and SF are determined for two qualitatively different states: when the box does not have contacts with the vertical guides of the axle gap of the SF and when these contacts have already arisen.

Power ties of wheel pairs with rails are determined by the conditions of their mutual contact combined with the rolling and sliding processes of the wheels (pseudo-slip) as well as the slip of ridges along the side faces of the rails.

In determining the horizontal force reactions between wheels and rails, two kinds of interaction between wheels and rails are taken into account: when the crests of the wheels do not touch the rails (free rolling of the gears) and when the forces acting normal to the rail (guided motion of the gear unit) act between the crests of the wheels and the rails.

When driving on wheels of wheel pairs, whose wheels are rigidly connected to each other by an axis at any moment of time, any wheel of the wheel pair inevitably slips along and across the rails. It is especially significant that such wheel slides in the movement of vehicles in the curved sections of the path of small radius. According to a special technique, the ratio of frictional-sliding moments on wheels of a wheel pair determines which of the wheels is slipping when the wheel pair moves and which rolls without sliding, the conditions for contacting the crests of the wheels with the side surface of the railhead are determined. The mode of movement of the wheel pair is taken into account: coasting, traction, braking.
Two types of interaction between wheels and rails are possible: when the crests of the wheels do not touch the rails (freewheeling of the wheel pair) and when the forces normal to the rail act (the direction of movement of the wheel pair) between the wheel crests and the rails.

Free wheel-free contact with the rails takes place if:

$$
\left|\delta_{3 a 3}+\Delta \delta_{3 a 3}+y_{\text {jom }}\right|-(-1)^{\mathrm{i}} \cdot q_{i} \geq 0
$$

where $\delta_{3 a_{3}}$ is the total clearance between the crests of wheels of the wheel pair and the side faces of the railheads, at the point where $i$ wheel; $\Delta \delta_{3 a 3}$ is the broadening of the path at the same point including the unevenness of the path in the plan; $y_{j o m}$ is the rail release under $i$ wheel $j$ wheel pair; $q_{i}$ is the generalized coordinate $i$ wheel pair $(i=5 \ldots 9)$.

During the free rolling between the wheel and the rail frictional forces can arise which keep the wheel from slipping over the inclined surface of the railhead (with rails flat) and forces caused by pseudo-slip as a result of rolling the wheel along the railhead at some angle to the longitudinal axis of the rail.

The total horizontal shear force acting on the $i$ wheel with free rolling will be equal to the sum of these forces:

$$
Y_{\delta i c b}=(-1)^{i}\left\{P_{w i} \cdot \sin \vartheta+k \cdot \operatorname{tg} \varphi_{b} \cdot \operatorname{sign} \dot{q}_{i}\right\}
$$

where $i=1 \ldots 4 ; P_{w i}$ is the vertical load from $i$ wheel to rail; $\vartheta$ is the angle of inclination to the horizon of the upper surface of the railhead (rails rails); $k$ is the coefficient of creep (pseudo-slip).

Force $Y_{\delta i}$ causes the rail to be released. With a known value of lateral force $Y_{\delta}$, The steering force on $i$ (the oncoming wheel) will be equal to $Y_{H}=Y_{\delta i}+Y_{\delta i c b}$.

The mathematical model of the movement of a 4-axle car allows one to model the movements of an 8-axle and a multiaxle wagon. In this case individual differential equations and equations of dynamic reactions of bonds and external forces are adapted for the basic design scheme of an 8-axle car. For example, an 8-axle freight car will be presented as a nonlinear mechanical system consisting of 23 rigid bodies: 8-WP, 8-SF, 4-bolt and 2 connecting beams, 1 body with a load.

In accordance with the number of degrees of freedom accepted by the design scheme (Figure 4), the oscillations of the 8-axle car are described by a system of 54-differential equations of the second order. This system is conditionally divided into 3 groups of differential equations where the first two describe the motion of 4-axle bogies and the third group their dynamic connection with each other. Differential equations of dynamic coupling are recorded through acceleration of wobble and lateral attitude of the center of mass of the body:

$$
\ddot{\varphi}_{\mathrm{K}}=\frac{\ddot{q}_{25}^{*}-\ddot{q}_{25}}{2 L} ; \quad \quad \ddot{y}_{\mathrm{K}}=\frac{\ddot{q}_{25}^{*}+\ddot{q}_{25}}{2}
$$

The influence of the moments of frictional forces on the oscillations of the wobbling of the connecting beams is taken into account in the corresponding differential equations analogous to the equation for wagging the body of a 4-axle car 
by adding a term where the radii of the central Friday of an 8axle car are substituted.

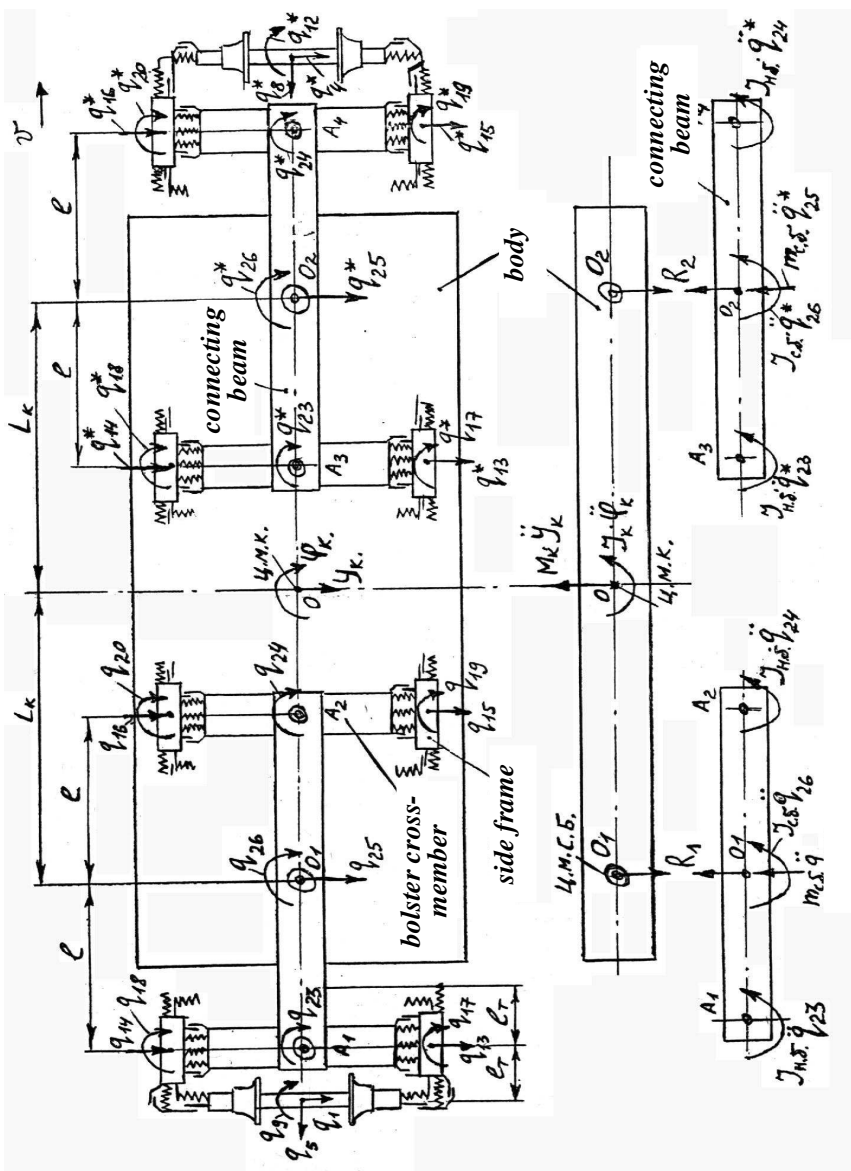

Fig. 4. The calculation scheme of the eight-axle vehicle

Accelerations $\ddot{q}_{25}^{*}$ and $\ddot{q}_{25}$ are necessary for dynamic coupling equations (4):

$$
\left\{\begin{array}{l}
\ddot{q}_{25}=\left(B \cdot Q^{*}-A \cdot Q\right) \cdot C \\
\ddot{q}_{25}^{*}=\left(B \cdot Q-A \cdot Q^{*}\right) \cdot C
\end{array}\right.
$$

where $A=\left(M_{\mathrm{K}}+4 \cdot m_{\text {с.б. }}\right) \cdot L_{\mathrm{K}}^{2}+J_{\mathrm{K}}$;

$$
\begin{aligned}
& B=M_{b} \cdot L_{\kappa}^{2}-J_{\kappa} ; \\
& C=4 \cdot L_{\kappa}^{2} /\left(A^{2}-B^{2}\right) ; \\
& Q=\sum_{1}^{4} Q_{H . \sigma .}+m_{c . \sigma .} \cdot\left(g \cdot Q_{11}-v \cdot \dot{\varphi}_{11}\right) ; \\
& Q^{*}=\sum_{1}^{4} Q_{\text {H.б. }}^{*}+m_{c . \sigma .} \cdot\left(g \cdot Q_{11}-v \cdot \dot{\varphi}_{11}^{*}\right) .
\end{aligned}
$$

\section{RESULTS AND DISCUSSION}

The obtained results of numerical simulation showed satisfactory convergence with the experimental data, which indicates the reliability of the developed mathematical model of the wagon motion in conditions of real combinations of deviations from the standards of maintenance in the vehicle and the path.

The proposed mathematical model allows one:

- to receive any output parameters in time as well as extreme values of linear and angular displacements, velocities and accelerations of all elements of the railway vehicle, deformations and forces in bonds, frame, lateral and directing forces, stability factors from derailment, recession angles, factors wear and the coefficients of dynamic forces additions for each element of the running parts of the vehicle;

- to vary geometric, rigid and inertial parameters of the running gear of the vehicle;

- to investigate the driving performance indicators used to estimate the vibrations of the sprung parts of the railway vehicles (dynamic factors, vertical and lateral acceleration of individual body points, etc.), safety used to estimate the dynamic behavior of uncured masses (wheel stability factors against the derailment, frame and side forces, the ratio of the frame force to the static axial load, etc.);

- to investigate the motion of the vehicle with different profiles of wheels and rails, rigidity characteristics of the track using creep forces models and friction coefficient values in the contact of the wheel and rail;

- to investigate the processes of rolling the wheel with a crest onto the railhead detaching the surface of the wheel from the rail and also the process of the wheel pair falling off the rails;

- to select rational parameters of the railway vehicle for the purpose of ensuring the safety of various types of railway vehicles and increasing their overhaul mileage.

\section{CONCLUSIONS}

1. An improved mathematical model of the movement of the railway vehicles has been developed taking into account deviations in the content of the running parts of the vehicle and the path with a variable structure of the system of nonlinear differential equations of motion.

2. The mathematical model allows one to investigate the movement, dynamic properties of the railway vehicles taking into account the real combinations of the maximum permissible wear of the running parts of the vehicles and the track and also to choose the rational parameters of the railway vehicle for various geometric, rigid and inertial parameters of the undercarriage.

\section{References}

[1] J.J. Kalker, "A fast algorithm for the simplified theory of rolling contact", Vehicle System Dynamics, 1982, vol. 11, no. 1, pp. 1-13.

[2] J. Piotrowski and W. Kik, "A simplified model of wheel/rail contact mechanics for non-Hertzian problems and its applcation in rail vehicle dynamic simulations“, Vehicle System Dynamics, 2008, vol. 46(1-2), pp. 27-48.

[3] R. Kovalev, N. Lysikov, G. Mikheev, D. Pogorelov, V. Simonov and V. Yazykov, "Freight car models and their computer-aided dinamic analysis“, Multibody System Dynamics, 2009, vol. 22(4), pp. 399-423.

[4] A.A. Shabana, "Dynamics of Multidody Systems", $4^{\text {th }}$ ed., Cambridge University Press, 2013, 384 p.

[5] A.V.Smolyaninov and A.R. Yaupov, "Sravnitelnyy analiz metodik rascheta ustoychivosti kolesnoy pary ot skhoda s relsov" ["Comparative Analysis of Methods of Calculation of Wheelsets Stability Against Derailment"]. Transport Urala [The Transport of Ural], 2016, no. 2, pp. 48-54. DOI: 10/20291/1815-9400-2016-2-48-54 (In Russian). 
[6] D.Ya. Antipin, O.V. Izmerov, S.G. Bishutin, V.V. Kobishchanov, "Group traction drive as means to increase energy efficiency of lokomotives of open-pit transport", IOP Conference Series: Earth and Environmental Science, 2017, no. 87(8). DOI: 10.1088/1755-1315-87-8082004.

[7] D.Ya. Antipin, D.A Bondarenko, O.V. Izmerov, "Study of Dynamic Loads in Traction Drive of Freight Locomotive under the Influence of Railway Track Irregularities", Procedia Engineering, 2017, vol. 206, pp. 1583-1586.

[8] E.A.H. Vollebregt, "User guide for CONTACT", Rolling and sliding contact with friction: report TR09-03, version 18.1, Delft (The Netherlands), VORtech BV, 2018, 135 p.

[9] Yu.M. Cherkashin, D.Yu. Pogorelov and V.A. Simonov, "Vliyanie parametrov ekipazhey i puti na bezopasnost' dvizheniya poezdov" ["Influence of parameters of vehicles and ways to safety of train traffic"]. Vestnik VNIIZhT [Vestnik of the Railway Research Institute], 2010, no. 2, pp. 3-9. (In Russian).

[10] D.V. Ivanov, "Vliyanie tekhnicheskogo sostoyaniya khodovykh chastey gruzovykh vagonov na bezopasnost' dvizheniya i iznos $\mathrm{v}$ sisteme «koleso-rel's»" [Influence of technical condition of running parts of freight cars on traffic safety and wear in the system "wheel-rail"], Ph.D. Thesis, Moscow, Moscow University of Railway Engineering, 2010, 201 p. (In Russian).

[11] A.A. Permyakov, "Bezopasnost' dvizheniya vagona v krivykh uchastkakh puti pri razlichnykh tekhnicheskikh sochetaniyakh sistemy «vagon - put'»" ["Safety of the car motion in the curved sections of the road with various technical combinations of the "car-track" system"], Ph.D. Thesis, Ekaterinburg, Ural State University of Railway Transport, 2004, 175 p. (In Russian).

[12] S.M. Zakharov and Yu.S. Romen, "Matematicheskoe modelirovanie vliyaniya parametrov puti i podvizhnogo sostava na protsessy iznashivaniya kolesa i rel'sa ["Mathematical modeling of the influence of track parameters and rolling stock on the wear process of the wheel and rail']. Vestnik VNIIZhT [Vestnik of the Railway Research Institute], 2010, no. 2, pp. 26-30. (In Russian).

[13] Yu.S. Romen, "Faktory obuslavlivayushchie processy vzaimodejstviya v sisteme koleso-rels pri dvizhenii poezda v krivyh ["Factors causing the interaction processes in the wheel-rail system when the train moves in curves"]. Vestnik VNIIZhT [Vestnik of the Railway Research Institute], 2015, no. 1, pp. 17-26. (In Russian).

[14] G.I. Petrov, D.V. Shpadi, A.G. Petrov, S.V. Kaletin, S.I. Poryadin and O.I. Panachev, "Osobennosti modelirovaniya silovykh svyazey pri komp'yuternom modelirovanii dvizheniya i skhoda kolesnoy pary vagona s uchetom kacheniya, podskal'zyvaniya i skol'zheniya oboda i grebnya kolesa po bokovoy grani golovki rel'sa" ["Peculiarities of modeling the power connections in the computer simulation of the motion and the derailment of a car wheel pair, taking into account the rolling, sliding and sliding of the rim and the crest of the wheel along the side face of the railhead']. Sbornik trudov XVI nauchno-prakticheskoy konferentsii "Bezopasnost' dvizheniya poezdov (BDP-2015)" [Collection of Proceedings of the XVI Scientific and Practical Conference "Traffic Safety of Trains (BDP-2015)"]. Moscow, Moscow University of Railway Engineering, 2015, pp. II-101-II-106. (In Russian).

[15] G.P. Burchak, A.N. Savoskin, G.N. Fradkin and V.S. Kossov "Metodika modelirovaniya dvizheniya relsovogo ehkipazha po puti s iskrivlennoj osyu" ["A technique for simulating the motion of a rail vehicle along a path with a curved axis"]. Trudy MGUPS [Proceedings of Moscow Transport University], Moscow, MGUPS, 1997, vol. 912, pp. 12-22. (In Russian).

[16] V.D. Khusidov, V.N. Filippov and G.I. Petrov, "Matematicheskaya model' i metodika issledovaniya prostranstvennyh kolebanij mnogoosnyh gruzovyh vagonov s razlichnymi skhemami hodovyh chastej i opornyh ustrojstv" ["Mathematical model and technique of investigation of spatial oscillations of multi-axle freight cars with various schemes of running parts and supporting devices"]. Moscow, MIIT, TSNIITEEItyazhmash, 1988, no. 2-TM88, 43 p. (In Russian). 